\title{
DEBATE Pense Grande Faça Pequeno
}

\section{Sylvain Levy'}

A frase que dá título a este artigo era uma das preferidas de Edmundo Juarez, sanitarista e professor de epidemiologia da Faculdade de Saúde Pública da USP. Juntamente com Rui Laurenti, João Antonio Neto Caminha, José Leão Costa, José da Rocha Carvalheiro, Jaci Teixeira da Silva, José Wanderley Ferreira e Sylvain Levy, Edmundo Juarez compunha o grupo que idealizou, planejou e implantou o Sistema de Informações sobre Mortalidade, que está completando 31 anos de operação ininterrupta. Sem dúvida um recorde nesse país de iniciativas efêmeras e passageiras.

O Sistema de Informações sobre Mortalidade - SIM, foi idealizado em 1975 e teve sua implantação iniciada no ano seguinte. Seu funcionamento atravessou regimes, governos, e governantes, dando uma mostra impactante, tanto da continuidade administrativa existente no setor saúde, quanto da importância de persistência, coordenação e clara definição das responsabilidades em um sistema de informação.

Este Sistema de Informações sobre Mortalidade foi concebido pela necessidade de se obter informações confiáveis, abrangentes e oportunas, quando, no Brasil de 1975, poderiam ser contados mais de 100 formulários diferentes de Atestados de Óbito, com as mais diversas estruturas administrativas e diferentes metodologias para coleta, processamento e apresentação de dados. Isso impedia qualquer possibilidade de se construir indicadores de abrangência nacional, regional e, algumas vezes, até mesmo estadual.

Ante tais dificuldades, era premente a criação de um sistema de informações, que “corresse" por dentro do sistema de saú- de, e que viesse a solucionar não apenas as limitações no manuseio de documentos de registro civil, mas, fundamentalmente, que também servisse para que ações de vigilância epidemiológica e de reconhecimento das doenças transmissíveis pudessem ser, rapidamente, postas em prática.

Em seu primeiro ano, o SIM conseguiu recolher dados de 220 mil Declarações de Óbito - DO, de alguns municípios de capitais. Em 77 ganhou abrangência nacional e chegou a 550 mil DO's coletadas, embora $47 \%$ a menos do que os 806.339 Atestados de Óbito recolhidos pelo IBGE junto aos cartórios.

Os resultados dessa continuidade política-administrativa podem ser aquilatados nos números de 2004 - 1.024.073 óbitos recolhidos pelo SIM e 1.137.033 registrados pelo sistema do IBGE.

Esta diferença, que permanece, embora tedo caído para $11 \%$, deve ser debitada a dois fatores. O primeiro está relacionado ao fato do IBGE registrar óbitos de anos anteriores, o que pode representar cerca de $4 \%$ do total. O segundo fator é a ainda deficiente cobertura do SIM em algumas regiões. Enquanto no Sul, Sudeste e Centro-Oeste o sistema tem conhecimento de $100 \%$ dos óbitos ocorridos, no Norte a cobertura é de $76 \%$ e no Nordeste de $80 \%$, sendo o Maranhão o estado onde se encontra o maior sub-registro, estimado em $46 \%$ dos óbitos acontecidos e não informados ao sistema de saúde.

Os esforços do Ministério e das Secretarias Estaduais e Municipais de Saúde, além de vários órgãos estaduais empenhados na implantação do Sistema, revelaram-se fundamentais para permitir, ao

${ }^{1}$ Médico Sanitarista e Psicanalista 
país, trabalhar, organizada e conscientemente, com dados epidemiológicos cada vez mais confiáveis, na redução e controle dos agravos de saúde que atormentam a população.

A idéia "Pense grande e faça pequeno" cabe como uma luva no processo de operação do SIM. A meta de alcançar todo o país, sempre foi ambiciosa. Mas as dificuldades para implantação e operação em abrangência nacional também sempre fo- ram previstas. Daí a opção pela implementação gradativa e com sucesso evidente.

Não há nenhuma dúvida de que o SIM colaborou para se saber como morrem os brasileiros e assim contribuiu para se conhecer como vivem e como pode ser melhorada sua qualidade de vida, sendo um exemplo prático e simples de política pública conduzida por servidores públicos ao longo do tempo.

\section{Gripe Aviária - Atualização da OMS - Março 2007}

\section{Cumulative Number of Confirmed Human Cases of Avian Influenza A/ (H5N1) Reported to WHO}

29 March 2007

\begin{tabular}{|c|c|c|c|c|c|c|c|c|c|c|c|c|}
\hline \multirow[t]{2}{*}{ Country } & \multicolumn{2}{|c|}{2003} & \multicolumn{2}{|c|}{2004} & \multicolumn{2}{|c|}{2005} & \multicolumn{2}{|c|}{2006} & \multicolumn{2}{|c|}{2007} & \multicolumn{2}{|c|}{ Total } \\
\hline & cases & deaths & cases & deaths & cases & deaths & cases & deaths & cases & deaths & cases & deaths \\
\hline Azerbaijan & 0 & 0 & 0 & 0 & 0 & 0 & 8 & 5 & 0 & 0 & 8 & 5 \\
\hline Cambodia & 0 & 0 & 0 & 0 & 4 & 4 & 2 & 2 & 0 & 0 & 6 & 6 \\
\hline China & 1 & 1 & 0 & 0 & 8 & 5 & 13 & 8 & 2 & 1 & 24 & 15 \\
\hline Djibouti & 0 & 0 & 0 & 0 & 0 & 0 & 1 & 0 & 0 & 0 & 1 & 0 \\
\hline Egypt & 0 & 0 & 0 & 0 & 0 & 0 & 18 & 10 & 11 & 3 & 29 & 13 \\
\hline Indonesia & 0 & 0 & 0 & 0 & 20 & 13 & 55 & 45 & 6 & 5 & 81 & 63 \\
\hline Iraq & 0 & 0 & 0 & 0 & 0 & 0 & 3 & 2 & 0 & 0 & 3 & 2 \\
\hline Lao People's Democratic & 0 & 0 & 0 & 0 & 0 & 0 & 0 & 0 & 2 & 2 & 2 & 2 \\
\hline Republic & & & & & & & & & & & & \\
\hline Nigeria & 0 & 0 & 0 & 0 & 0 & 0 & 0 & 0 & 1 & 1 & 1 & 1 \\
\hline Thailand & 0 & 0 & 17 & 12 & 5 & 2 & 3 & 3 & 0 & 0 & 25 & 17 \\
\hline Turkey & 0 & 0 & 0 & 0 & 0 & 0 & 12 & 4 & 0 & 0 & 12 & 4 \\
\hline Viet Nam & 3 & 3 & 29 & 20 & 61 & 19 & 0 & 0 & 0 & 0 & 93 & 42 \\
\hline Total & 4 & 4 & 46 & 32 & 98 & 43 & 115 & 79 & 22 & 12 & 285 & 170 \\
\hline
\end{tabular}

Total number of cases includes number of deaths. WHO reports only laboratory-confirmed cases. All dates refer to onset of illness. 